\title{
SARS-CoV-2 mass vaccination: Urgent questions on vaccine safety that demand answers from international health agencies, regulatory authorities, governments and vaccine developers
}

Roxana Bruno ${ }^{1}$, Peter A Mccullough ${ }^{2}$, Teresa Forcades I Vila ${ }^{3}$, Alexandra Henrion-Caude ${ }^{4}$, Teresa García-Gasca ${ }^{5}$, Galina P Zaitzeva ${ }^{6}$, Sally Priester ${ }^{7}$, María J Martínez Albarracín ${ }^{8}$, Alejandro Sousa-Escandon ${ }^{9}$, Fernando López Mirones ${ }^{10}$, Bartomeu Payeras Cifre ${ }^{11}$, Almudena Zaragoza Velilla ${ }^{10}$, Leopoldo M Borini ${ }^{1}$, Mario Mas $^{1}$, Ramiro Salazar ${ }^{1}$, Edgardo Schinder ${ }^{1}$, Eduardo A Yahbes ${ }^{1}$, Marcela Witt ${ }^{1}$, Mariana Salmeron ${ }^{1}$, Patricia Fernández ${ }^{1}$, Miriam M Marchesini ${ }^{1}$, Alberto J Kajihara ${ }^{1}$, Marisol V De La Riva ${ }^{1}$, Patricia J Chimeno ${ }^{1}$, Paola A Grellet ${ }^{1}$, Matelda Lisdero ${ }^{1}$, Pamela Mas ${ }^{1}$, Abelardo J Gatica Baudo ${ }^{12}$, Elisabeth Retamoza $^{12}$, Oscar Botta ${ }^{13}$, Chinda C Brandolino ${ }^{13}$, Javier Sciuto ${ }^{14}$, Mario Cabrera Avivar $^{14}$, Mauricio Castillo ${ }^{15}$, Patricio Villarroe ${ }^{15}$, Emilia P Poblete Rojas ${ }^{15}$, Bárbara Aguayo $^{15}$, Dan I Macías Flores ${ }^{15}$, Jose V Rossell ${ }^{16}$, Julio C Sarmiento ${ }^{17}$, Victor Andrade-Sotomayor ${ }^{17}$, Wilfredo R Stokes Baltazar ${ }^{18}$, Virna Cedeño Escobar ${ }^{19}$, Ulises Arrúa $^{20}$, Atilio Farina del Río ${ }^{21}$, Tatiana Campos Esquivel ${ }^{22}$, Patricia Callisperis ${ }^{23}$, María Eugenia Barrientos ${ }^{24}$, Christian Fiala ${ }^{25}$, and Karina Acevedo-Whitehouse ${ }^{26}$

${ }^{1}$ Epidemiólogos Argentinos Metadisciplinarios

${ }^{2}$ Baylor University Medical Center

${ }^{3}$ Monestir de Sant Benet de Montserrat

${ }^{4}$ Simplissima International Research Institute, Mauritius.

${ }^{5}$ School of Natural Sciences, Autonomous University of Querétaro

${ }^{6}$ Retired Professor of Medical Immunology. Universidad de Guadalajara. Mexico

${ }^{7}$ Médicos por la Verdad Puerto Rico

${ }^{8}$ Retired Professor of Clinical Diagnostic Processes. University of Murcia. Spain

${ }^{9}$ Hospital Comarcal de Monforte, University of Santiago de Compostela, Spain

${ }^{10}$ Biólogos por la Verdad, España

${ }^{11}$ Retired Biologist. University of Barcelona. Specialized in Microbiology. Spain

${ }^{12}$ Center for Integrative Medicine MICAEL (Medicina Integrativa Centro Antroposófico

Educando en Libertad). Argentina

${ }^{13}$ Médicos por la Verdad Argentina

${ }^{14}$ Médicos por la Verdad Uruguay

${ }^{15}$ Médicos por la Libertad Chile

${ }^{16}$ Physician, orthopedic specialist. Chile

${ }^{17}$ Médicos por la Verdad Perú

${ }^{18}$ Médicos por la Verdad Guatemala

${ }^{19}$ Centro de Biotecnologías Ómicas (CEBIOMICS) - Concepto Azul, Ecuador

${ }^{20}$ Médicos por la Verdad Brasil

${ }^{21}$ Médicos por la Verdad Paraguay 
${ }^{22}$ Médicos por la Verdad Costa Rica

${ }^{23}$ Médicos por la Verdad Bolivia

${ }^{24}$ Médicos por la Verdad El Salvador

${ }^{25}$ Gynmed Ambulatorium, Vienna. Austria

${ }^{26}$ Affiliation not available

May 24, 2021

\begin{abstract}
Since the start of the COVID-19 outbreak, the race for testing new platforms designed to confer immunity against SARS-CoV-2, has been rampant and unprecedented, leading to conditional emergency authorization of various vaccines. Despite progress on early multidrug therapy for COVID-19 patients, the current mandate is to immunize the world population as quickly as possible. The lack of thorough testing in animals prior to clinical trials, and authorization based on safety data generated during trials that lasted less than 3.5 months, raise questions regarding vaccine safety. The recently identified role of SARS-CoV-2 Spike glycoprotein for inducing endothelial damage characteristic of COVID-19, even in absence of infection, is extremely relevant given that most of the authorized vaccines induce endogenous production of Spike. Given the high rate of occurrence of adverse effects that have been reported to date, as well as the potential for vaccine-driven disease enhancement, Th2-immunopathology, autoimmunity, and immune evasion, there is a need for a better understanding of the benefits and risks of mass vaccination, particularly in groups excluded from clinical trials. Despite calls for caution, the risks of SARS-CoV-2 vaccination have been minimized or ignored by health organizations and government authorities. As for any investigational biomedical program, data safety monitoring boards (DSMB) and event adjudication committees (EAC), should be enacting risk mitigation. If DSMBs and EACs do not do so, we will call for a pause in mass vaccination. If DSMBs and EACs do not exist, then vaccination should be halted immediately, in particular for demographic groups at highest risk of vaccine-associated death or serious adverse effects, during such time as it takes to assemble these boards and commence critical and independent assessments. We urge for pluralistic dialogue in the context of health policies, emphasizing critical questions that require urgent answers, particularly if we wish to avoid a global erosion of public confidence in science and public health.
\end{abstract}

SARS-CoV-2 mass vaccination: Urgent questions on vaccine safety that demand answers from international health agencies, regulatory authorities, governments and vaccine developers

Roxana Bruno ${ }^{1}$, Peter A. McCullough ${ }^{2}$, Teresa Forcades i Vila ${ }^{3}$, Alexandra Henrion-Caude ${ }^{4}$, Teresa GarcíaGasca $^{5}$, Galina P. Zaitzeva ${ }^{6}$, Sally Priester ${ }^{7}$, María J. Martínez Albarracín ${ }^{8}$, Alejandro Sousa-Escandon ${ }^{9}$, Fernando López Mirones ${ }^{10}$, Bartomeu Payeras Cifre ${ }^{11}$, Almudena Zaragoza Velilla ${ }^{10}$, Leopoldo M. Borini ${ }^{1}$, Mario Mas $^{1}$, Ramiro Salazar ${ }^{1}$, Edgardo Schinder ${ }^{1}$, Eduardo A. Yahbes ${ }^{1}$, Marcela Witt ${ }^{1}$, Mariana Salmeron ${ }^{1}$, Patricia Fernández ${ }^{1}$, Miriam M. Marchesini ${ }^{1}$, Alberto J. Kajihara ${ }^{1}$, Marisol V. de la Riva ${ }^{1}$, Patricia J. Chimeno ${ }^{1}$, Paola A. Grellet ${ }^{1}$, Matelda Lisdero ${ }^{1}$, Pamela Mas $^{1}$, Abelardo J. Gatica Baudo ${ }^{12}$, Elisabeth Retamoza ${ }^{12}$, Oscar Botta ${ }^{13}$, Chinda C. Brandolino ${ }^{13}$, Javier Sciuto ${ }^{14}$, Mario Cabrera Avivar ${ }^{14}$, Mauricio Castillo ${ }^{15}$, Patricio Villarroel ${ }^{15}$, Emilia P. Poblete Rojas ${ }^{15}$, Bárbara Aguayo ${ }^{15}$, Dan I. Macías Flores ${ }^{15}$, Jose V. Rossell ${ }^{16}$, Julio C. Sarmiento ${ }^{17}$, Victor Andrade-Sotomayor ${ }^{17}$, Wilfredo R. Stokes Baltazar ${ }^{18}$, Virna Cedeño Escobar ${ }^{19}$, Ulises Arrúa ${ }^{20}$, Atilio Farina del Río ${ }^{21}$, Tatiana Campos Esquivel ${ }^{22}$, Patricia Callisperis ${ }^{23}$, María Eugenia Barrientos $^{24}$, Christian Fiala ${ }^{25}$, Karina Acevedo-Whitehouse ${ }^{5, *}$.

${ }^{1}$ Epidemiólogos Argentinos Metadisciplinarios. Argentina.

${ }^{2}$ Baylor University Medical Center. Dallas, Texas. USA.

${ }^{3}$ Monestir de Sant Benet de Montserrat, Montserrat. Spain 
4 Simplissima International Research Institute. Mauritius.

5 School of Natural Sciences. Autonomous University of Querétaro. Mexico.

${ }^{6}$ Retired Professor of Medical Immunology. Universidad de Guadalajara. Mexico.

7 Médicos por la Verdad Puerto Rico. Ashford Medical Center, San Juan. Puerto Rico.

8 Retired Professor of Clinical Diagnostic Processes. University of Murcia. Spain.

${ }^{9}$ Hospital Comarcal de Monforte, University of Santiago de Compostela, Spain.

10 Biólogos por la Verdad. Spain.

11 Retired Biologist. University of Barcelona. Specialized in Microbiology. Spain.

12 Center for Integrative Medicine MICAEL (Medicina Integrativa Centro Antroposófico Educando en Libertad). Argentina.

13 Médicos por la Verdad. Argentina.

14 Médicos por la Verdad. Uruguay.

15 Médicos por la Libertad. Chile.

16 Physician, orthopedic specialist. Chile.

17 Médicos por la Verdad. Perú.

18 Médicos por la Verdad. Guatemala.

19 Centro de Biotecnologías Ómicas (CEBIOMICS) - Concepto Azul, Ecuador.

20 Médicos por la Verdad. Brasil.

21 Médicos por la Verdad. Paraguay.

22 Médicos por la Verdad. Costa Rica.

23 Médicos por la Verdad. Bolivia.

24 Médicos por la Verdad. El Salvador.

25 Gynmed Ambulatorium, Vienna. Austria.

${ }^{*}$ Corresponding author

\begin{abstract}
Since the start of the COVID-19 outbreak, the race for testing new platforms designed to confer immunity against SARS-CoV-2, has been rampant and unprecedented, leading to conditional emergency authorization of various vaccines. Despite progress on early multidrug therapy for COVID-19 patients, the current mandate is to immunize the world population as quickly as possible. The lack of thorough testing in animals prior to clinical trials, and authorization based on safety data generated during trials that lasted less than 3.5 months, raise questions regarding vaccine safety. The recently identified role of SARS-CoV-2 Spike glycoprotein for inducing endothelial damage characteristic of COVID-19, even in absence of infection, is extremely relevant given that most of the authorized vaccines induce endogenous production of Spike. Given the high rate of occurrence of adverse effects that have been reported to date, as well as the potential for vaccine-driven disease enhancement, Th2-immunopathology, autoimmunity, and immune evasion, there is a need for a better understanding of the benefits and risks of mass vaccination, particularly in groups excluded from clinical trials. Despite calls for caution, the risks of SARS-CoV-2 vaccination have been minimized or ignored by health organizations and government authorities. As for any investigational biomedical program, data safety
\end{abstract}


monitoring boards (DSMB) and event adjudication committees (EAC), should be enacting risk mitigation. If DSMBs and EACs do not do so, we will call for a pause in mass vaccination. If DSMBs and EACs do not exist, then vaccination should be halted immediately, in particular for demographic groups at highest risk of vaccine-associated death or serious adverse effects, during such time as it takes to assemble these boards and commence critical and independent assessments. We urge for pluralistic dialogue in the context of health policies, emphasizing critical questions that require urgent answers, particularly if we wish to avoid a global erosion of public confidence in science and public health.

\section{Introduction}

Since COVID-19 was declared a pandemic in March 2020, over 150 million cases and 3 million cases of deaths from or with SARS-CoV-2 have been reported worldwide. Despite progress on early ambulatory, multidrugtherapy for high-risk patients, resulting in 85\% reductions in COVID-19 hospitalization and death [1], the current paradigm for control is mass-vaccination. While we recognize the effort involved in development, production and emergency authorization of SARS-CoV-2 vaccines, we are concerned that risks have been minimized or ignored by health organizations and government authorities, despite calls for caution [2-8].

Vaccines for other coronaviruses have never been approved for humans, and data generated in the development of coronavirus vaccines designed to elicit neutralizing antibodies show that they may worsen COVID-19 disease via antibody-dependent enhancement (ADE) and Th2 immunopathology, regardless of the vaccine platform and delivery method [9-11]. Vaccine-driven disease enhancement in animals vaccinated against SARS-CoV and MERS-CoV is known to occur following viral challenge, and has been attributed to immune complexes and Fc-mediated viral capture by macrophages, which augment T-cell activation and inflammation [11-13].

In March 2020, vaccine immunologists and coronavirus experts assessed SARS-CoV-2 vaccine risks based on SARS-CoV-vaccine trials in animal models. The expert group concluded that ADE and immunopathology were a real concern, but stated that their risk was insufficient to delay clinical trials, although continued monitoring would be necessary [14]. While there is no clear evidence of the occurrence of ADE and vaccinerelated immunopathology in volunteers immunized with SARS-CoV-2 vaccines [15], safety trials to date have not specifically addressed these serious adverse effects (SAE). Given that the follow-up of volunteers did not exceed 2-3.5 months after the second dose [16-19], it is unlikely such SAE would have been observed. Despite errors in reporting, it cannot be ignored that even accounting for the number of vaccines administered, according to the US Vaccine Adverse Effect Reporting System (VAERS), the number of deaths per million vaccine doses administered has increased more than 10 -fold. We believe there is an urgent need for open scientific dialogue on vaccine safety in the context of large-scale immunization. In this paper, we describe some of the risks of mass vaccination in the context of phase 3 trial exclusion criteria and discuss the SAE reported in national and regional adverse effect registration systems. We highlight unanswered questions and draw attention to the need for a more cautious approach to mass vaccination.

\section{SARS-CoV-2 phase 3 trial exclusion criteria}

With few exceptions, SARS-CoV-2 vaccine trials excluded the elderly [16-19], making it impossible to identify the occurrence of post-vaccination eosinophilia and enhanced inflammation in elderly people. Studies of SARS-CoV vaccines showed that immunized elderly mice were at particularly high risk of life-threatening 
Th2 immunopathology $[9,20]$. Despite this evidence and the extremely limited data on safety and efficacy of SARS-CoV-2 vaccines in the elderly, mass-vaccination campaigns have focused on this age group from the start. Most trials also excluded pregnant and lactating volunteers, as well as those with chronic and serious conditions such as tuberculosis, hepatitis C, autoimmunity, coagulopathies, cancer, and immune suppression [16-29], although these recipients are now being offered the vaccine under the premise of safety.

Another criterion for exclusion from nearly all trials was prior exposure to SARS-CoV-2. This is unfortunate as it denied the opportunity of obtaining extremely relevant information concerning post-vaccination ADE in people that already have anti-SARS-Cov-2 antibodies. To the best of our knowledge, ADE is not being monitored systematically for any age or medical condition group currently being administered the vaccine. Moreover, despite a substantial proportion of the population already having antibodies [21], tests to determine SARS-CoV-2-antibody status prior to administration of the vaccine are not conducted routinely.

\section{Will serious adverse effects from the SARS-CoV-2 vaccines go unnoticed?}

COVID-19 encompasses a wide clinical spectrum, ranging from very mild to severe pulmonary pathology and fatal multi-organ disease with inflammatory, cardiovascular, and blood coagulation dysregulation [22-24]. In this sense, cases of vaccine-related ADE or immunopathology would be clinically-indistinguishable from severe COVID-19 [25]. Furthermore, even in the absence of SARS-CoV-2 virus, Spike glycoprotein alone causes endothelial damage and hypertension in vitro and in vivo in Syrian hamsters by down-regulating angiotensin-converting enzyme 2 (ACE2) and impairing mitochondrial function [26]. Although these findings need to be confirmed in humans, the implications of this finding are staggering, as all vaccines authorized for emergency use are based on the delivery or induction of Spike glycoprotein synthesis. In the case of mRNA vaccines and adenovirus-vectorized vaccines, not a single study has examined the duration of Spike production in humans following vaccination. Under the cautionary principle, it is parsimonious to consider vaccine-induced Spike synthesis could cause clinical signs of severe COVID-19, and erroneously be counted as new cases of SARS-CoV-2 infections. If so, the true adverse effects of the current global vaccination strategy may never be recognized unless studies specifically examine this question. There is already noncausal evidence of temporary or sustained increases in COVID-19 deaths following vaccination in some countries (Fig. 1) and in light of Spike's pathogenicity, these deaths must be studied in depth to determine whether they are related to vaccination.

\section{Unanticipated adverse reactions to SARS-CoV-2 vaccines}

Another critical issue to consider given the global scale of SARS-CoV-2 vaccination is autoimmunity. SARS$\mathrm{CoV}-2$ has numerous immunogenic proteins, and all but one of its immunogenic epitopes have similarities to human proteins [27]. These may act as a source of antigens, leading to autoimmunity [28]. While it is true that the same effects could be observed during natural infection with SARS-CoV-2, vaccination is intended for most of the world population, while it is estimated that only $10 \%$ of the world population has been infected by SARS-CoV-2, according to Dr. Michael Ryan, head of emergencies at the World Health Organization. We have been unable to find evidence that any of the currently authorized vaccines screened and excluded homologous immunogenic epitopes to avoid potential autoimmunity due to pathogenic priming.

Some adverse reactions, including blood-clotting disorders, have already been reported in healthy and young vaccinated people. These cases led to the suspension or cancellation of the use of adenoviral vec- 
torized ChAdOx1-nCov-19 and Janssen vaccines in some countries. It has now been proposed that vaccination with ChAdOx1-nCov-19 can result in immune thrombotic thrombocytopenia (VITT) mediated by platelet-activating antibodies against Platelet factor-4, which clinically mimics autoimmune heparin-induced thrombocytopenia [29]. Unfortunately, the risk was overlooked when authorizing these vaccines, although adenovirus-induced thrombocytopenia has been known for more than a decade, and has been a consistent event with adenoviral vectors [30]. The risk of VITT would presumably be higher in those already at risk of blood clots, including women who use oral contraceptives [31], making it imperative for clinicians to advise their patients accordingly.

At the population level, there could also be vaccine-related impacts. SARS-CoV-2 is a fast-evolving RNA virus that has so far produced more than 40,000 variants $[32,33]$ some of which affect the antigenic domain of Spike glycoprotein $[34,35]$. Given the high mutation rates, vaccine-induced synthesis of high levels of anti-SARSCoV-2-Spike antibodies could theoretically lead to suboptimal responses against subsequent infections by other variants in vaccinated individuals [36], a phenomenon known as "original antigenic sin" [37] or antigenic priming [38]. It is unknown to what extent mutations that affect SARS-CoV-2 antigenicity will become fixed during viral evolution [39], but vaccines could plausibly act as selective forces driving variants with higher infectivity or transmissibility. Considering the high similarity between known SARS-CoV-2 variants, this scenario is unlikely $[32,34]$ but if future variants were to differ more in key epitopes, the global vaccination strategy might have helped shape an even more dangerous virus. This risk has recently been brought to the attention of the WHO as an open letter [40].

\section{Discussion}

The risks outlined here are a major obstacle to continuing global SARS-CoV-2 vaccination. Evidence on the safety of all SARS-CoV-2 vaccines is needed before exposing more people to the risk of these experiments, since releasing a candidate vaccine without time to fully understand the resulting impact on health could lead to an exacerbation of the current global crisis [41]. Risk-stratification of vaccine recipients is essential. According to the UK government, people below 60 years of age have an extremely low risk of dying from COVID-19[1]. However, according to Eudravigillance, most of the serious adverse effects following SARS$\mathrm{CoV}-2$ vaccination occur in people aged 18-64. Of particular concern is the planned vaccination schedule for children aged 6 years and older in the United States and the UK. Dr. Anthony Fauci recently anticipated that teenagers across the country will be vaccinated in the autumn and younger children in early 2022, and the UK is awaiting trial results to commence vaccination of 11 million children under 18 . There is a lack of scientific justification for subjecting healthy children to experimental vaccines, given that the Centers for Disease Control and Prevention estimates that they have a 99.997\% survival rate if infected with SARS-CoV-2. Not only is COVID-19 irrelevant as a threat to this age group, but there is no reliable evidence to support vaccine efficacy or effectiveness in this population or to rule out harmful side effects of these experimental vaccines. In this sense, when physicians advise patients on the elective administration of COVID-19 vaccination, there is a great need to better understand the benefits and risk of administration, particularly in understudied groups.

In conclusion, in the context of the rushed emergency-use-authorization of SARS-CoV-2 vaccines, and the current gaps in our understanding of their safety, the following questions must be raised:

* Is it known whether cross-reactive antibodies from previous coronavirus infections or vaccine-induced antibodies may influence the risk of unintended pathogenesis following vaccination with COVID-19? 
* Has the specific risk of ADE, immunopathology, autoimmunity, and serious adverse reactions been clearly disclosed to vaccine recipients to meet the medical ethics standard of patient understanding for informed consent? If not, what are the reasons, and how could it be implemented?

* What is the rationale for administering the vaccine to every individual when the risk of dying from COVID-19 is not equal across age groups and clinical conditions and when the phase 3 trials excluded the elderly, children and frequent specific conditions?

* What are the legal rights of patients if they are harmed by a SARS-CoV-2 vaccine? Who will cover the costs of medical treatment? If claims were to be settled with public money, has the public been made aware that the vaccine manufacturers have been granted immunity, and their responsibility to compensate those harmed by the vaccine has been transferred to the tax-payers?

If vaccination programs worldwide do not institute independent data safety monitoring boards (DSMB), event adjudication committees (EAC), and enact risk mitigation, we will call for a pause in the mass vaccination program. If DSMBs and EACs do not exist currently, as would be imperative for any investigational biomedical program, then vaccination should be immediately halted for those demographic groups at highest risk of vaccine-associated death or serious adverse effects, during the time it takes to assemble these boards and committees and commence their assessments.

In the context of these concerns, we propose opening an urgent pluralistic, critical, and scientifically-based dialogue on SARS-CoV-2 vaccination among scientists, medical doctors, international health agencies, regulatory authorities, governments, and vaccine developers. This is the only way to bridge the current gap between scientific evidence and public health policy regarding the SARS-CoV-2 vaccines. We are convinced that humanity deserves a deeper understanding of the risks than what is currently touted as the official position. An open scientific dialogue is urgent and indispensable to avoid erosion of public confidence in science and public health and to ensure that the WHO and national health authorities protect the interests of humanity during the current pandemic. Returning public health policy to evidence-based medicine, relying on a careful evaluation of the relevant scientific research, is urgent. It is imperative to follow the science.

\section{Conflict of Interest Statement}

The authors declare that the research was conducted in the absence of any commercial or financial relationships that could be construed as a potential conflict of interest.

\section{References}

1. McCullough PA, Alexander PE, Armstrong R, et al. Multifaceted highly targeted sequential multidrug treatment of early ambulatory high-risk SARS-CoV-2 infection (COVID-19). Rev Cardiovasc Med (2020) 21:517-530. doi:10.31083/j.rcm.2020.04.264 
2. Arvin AM, Fink K, Schmid MA, et al. A perspective on potential antibody- dependent enhancement of SARS-CoV-2. Nature (2020) 484:353-363. doi:10.1038/s41586-020-2538-8

3. Coish JM, MacNeil AJ. Out of the frying pan and into the fire? Due diligence warranted for ADE in COVID-19. Microbes Infect (2020) 22(9):405-406. doi:10.1016/j.micinf.2020.06.006

4. Eroshenko N, Gill T, Keaveney ML, et al. Implications of antibody-dependent enhancement of infection for SARS-CoV-2 countermeasures. Nature Biotechnol (2020) 38:788-797. doi:10.1038/s41587-020-0577-1

5. Poland GA. Tortoises, hares, and vaccines: A cautionary note for SARS-CoV-2 vaccine development. Vaccine (2020) 38:4219-4220. doi:10.1016/j.vaccine.2020.04.073

6. Shibo J. Don't rush to deploy COVID-19 vaccines and drugs without sufficient safety guarantees. Nature (2000) 579,321. doi:10.1038/d41586-020-00751-9

7. Munoz FA, Cramer JP, Dekker CL, et al. Vaccine-associated enhanced disease: Case definition and guidelines for data collection, analysis, and presentation of immunization safety data. Vaccine (2021) https://doi.org/10.1016/j.vaccine.2021.01.055

8. Cardozo T, Veazey R. Informed consent disclosure to vaccine trial subjects of risk of COVID-19 vaccines worsening clinical disease. Int J Clin Pract (2020) 28:e13795. doi: 10.1111/ijcp.13795

9. Bolles D, Long K, Adnihothram S, et al. A double-inactivated severe acute respiratory syndrome coronavirus vaccine provides incomplete protection in mice and induces increased eosinophilic proinflammatory pulmonary response upon challenge. J Virol (2001) 85:12201-12215. doi:10.1128/JVI.06048-11

10. Weingartl H, Czub M, Czub S, et al. Immunization with modified vaccinia virus Ankarabased recombinant vaccine against severe acute respiratory syndrome is associated with enhanced hepatitis in ferrets. J Virol (2004) 78:12672-12676. doi:10.1128/JVI.78.22.12672-12676.2004

11. Tseng CT, Sbrana E, Iwata-Yoshikawa N, et al. Immunization with SARS coronavirus vaccines leads to pulmonary immunopathology on challenge with the SARS virus. PLoS One (2012) 7(4):e35421. doi: 10.1371/journal.pone.0035421

12. Iwasaki A, Yang Y. The potential danger of suboptimal antibody responses in COVID-19. Nat Rev Immunol (2020) 20:339-341. doi:10.1038/s41577-020-0321-6

13. Vennema H, de Groot RJ, Harbour DA, et al. Early death after feline infectious peritonitis virus challenge due to recombinant vaccinia virus immunization. J Virol (1990) 64:1407-1409

14. Lambert PH, Ambrosino DM, Andersen SR, et al. Consensus summary report for CEPI/BC March 12-13, 2020 meeting: Assessment of risk of disease enhancement with COVID-19 vaccines. Vaccine (2020) 38(31):4783-4791. doi:10.1016/j.vaccine.2020.05.064

15. de Alwis R, Chen S, Gan S, et al. Impact of immune enhancement on Covid-19 polyclonal hyperimmune globulin therapy and vaccine development. EbioMedicine (2020) 55:102768. doi:10.1016/j.ebiom.2020.102768

16. Folegatti PM, Ewer KJ, Aley PK, et al. Safety and immunogenicity of the ChAdOx1 nCoV-19 vaccine against SARS-CoV-2: a preliminary report of a phase 1/2, single-blind, randomised controlled trial. Lancet (2020) 396:467-783. doi:10.1016/S0140-6736(20)31604-4

17. Polack FP, Thomas SJ, Kitchin N. Safety and efficacy of the BNT162b2 mRNA Covid-19 vaccine. $N$ Engl J Med (2020) 383:2603-2615. doi:10.1056/NEJMoa2034577

18. Ramasamy MN, Minassian AM, Ewer KJ, et al. Safety and immunogenicity of ChAdOx1 nCoV-19 vaccine administered in a prime-boost regimen in young and old adults (COV002): a single-blind, randomised, controlled, phase 2/3 trial. Lancet (2021) 396:1979-93. doi: 10.1016/S0140-6736(20)32466-1 
19. Chu L, McPhee R, Huang W, et al. mRNA-1273 Study Group. A preliminary report of a randomized controlled phase 2 trial of the safety and immunogenicity of mRNA-1273 SARS-CoV-2 vaccine. Vaccine (2021) S0264-410X(21)00153-5. doi:10.1016/j.vaccine.2021.02.007

20. Liu L, Wei Q, Lin Q, et al. Anti-spike IgG causes severe acute lung injury by skewing macrophage responses during acute SARS-CoV infection. JCI Insight (2019) 4(4):e123158. doi:10.1172/jci.insight.123158.

21. Ioannidis PA. Infection fatality rate of COVID-19 inferred from seroprevalence data. Bull WHO (2021) 99:19-33F. http://dx.doi.org/10.2471/BLT.20.265892

22. Martines RB, Ritter JM, Matkovic E, et al. Pathology and Pathogenesis of SARS-CoV2 Associated with Fatal Coronavirus Disease, United States Emerg Infect Dis (2020) 26:2005-2015. doi:10.3201/eid2609.202095

23. Wu Z, McGoogan JM. Characteristics of and Important Lessons From the Coronavirus Disease 2019 (COVID-19) Outbreak in China: Summary of a Report of 72314 Cases From the Chinese Center for Disease Control and Prevention. JAMA (2020) 323:1239-1242. doi:10.1001/jama.2020.2648

24. $\mathrm{Xu} \mathrm{Z}$, Shi L, Wang Y, et al. Pathological findings of COVID-19 associated with acute respiratory distress syndrome. Lancet Respiratory Med (2020) 8:420-422 doi:10.1016/S2213-2600(20)30076-X

25. Negro F. Is antibody-dependent enhancement playing a role in COVID-19 pathogenesis? Swiss Medical Weekly (2020) 150:w20249. doi:10.4414/smw.2020.20249

26. Lei Y, Zhang J, Schiavon CR et al., Spike Protein Impairs Endothelial Function via Downregulation of ACE 2. Circulation Res (2021) 128:1323-1326. https://doi.org/10.1161/CIRCRESAHA.121.318902

27. Lyons-Weiler J. Pathogenic priming likely contributes to serious and critical illness and mortality in COVID-19 via autoimmunity, $J$ Translational Autoimmunity (2020) 3:100051. doi:10.1016/j.jtauto.2020.100051

28. An H, Park J. Molecular Mimicry Map (3M) of SARS-CoV-2: Prediction of potentially immunopathogenic SARS-CoV-2 epitopes via a novel immunoinformatic approach. bioRxiv [Preprint]. 12 November 2020 [cited 2020 April 19] https://doi.org/10.1101/2020.11.12.344424

29. Greinacher A, Thiele T, Warkentin TE, Weisser K, Kyrle PA, Eichinger S. Thrombotic Thrombocytopenia after ChAdOx1 nCov-19 Vaccination. N Engl J Med (2021). doi: 10.1056/NEJMoa2104840

30. Othman M, Labelle A, Mazzetti I et al. Adenovirus-induced thrombocytopenia: the role of von Willebrand factor and P-selectin in mediating accelerated platelet clearance. Blood (2007) 109:2832-2839. doi:10.1182/blood-2006-06-032524

31. Ortel TL. Acquired thrombotic risk factors in the critical care setting. Crit Care Med (2010) 38(2 Suppl):S43-50. doi:10.1097/CCM.0b013e3181c9ccc8

32. Grubaugh ND, Petrone ME, Holmes EC. We shouldn't worry when a virus mutates during disease outbreaks. Nat Microbiol (2020) 5:529-530. https://doi.org/10.1038/s41564-020-0690-4

33. Greaney AJ, Starr TN, Gilchuk P, et al. Complete Mapping of Mutations to the SARS-CoV-2 Spike Receptor-Binding Domain that Escape Antibody Recognition. Cell Host Microbe (2021) 29:44-57.e9. doi:10.1016/j.chom.2020.11.007.

34. Lauring AS, Hodcroft EB. Genetic Variants of SARS-CoV-2 - What Do They Mean? JAMA (2021) 325:529-531. doi:10.1001/jama.2020.27124

35. Zhang L, Jackson CB, Mou H, et al. The D614G mutation in the SARS-CoV-2 spike protein reduces S1 shedding and increases infectivity. bioRxiv [Preprint]. June 122020 [cited 2021 Apr 19] https://doi.org/10.1101/2020.06.12.148726 
36. Korber B, Fischer WM, Gnanakaran S et al. Sheffield COVID-19 Genomics Group. Tracking changes in SARS-CoV-2 spike: evidence that D614G increases infectivity of the COVID-19 virus. Cell (2020) 182:812-827.e19. doi:10.1016/j.cell.2020.06.043

37. Francis T. On the doctrine of original antigenic sin. Proc Am Philos Soc (1960) 104:572-578.

38. Vibroud C, Epstein SL. First flu is forever. Science (2016) 354:706-707. doi:10.1126/science.aak9816

39. Weisblum Y, Schmidt F, Zhang F, et al. Escape from neutralizing antibodies by SARS-CoV-2 spike protein variants. Elife (2020) 9:e61312. doi:10.7554/eLife.61312

40. Vanden Bossche G (March 6, 2021) https://dryburgh.com/wp-content/uploads/2021/03/Geert_ Vanden_Bossche_Open_Letter_WHO_March_6_2021.pdf

41. Coish JM, MacNeil AJ. Out of the frying pan and into the fire? Due diligence warranted for ADE in COVID-19. Microbes Infect (2020) 22(9):405-406. doi:10.1016/j.micinf.2020.06.006
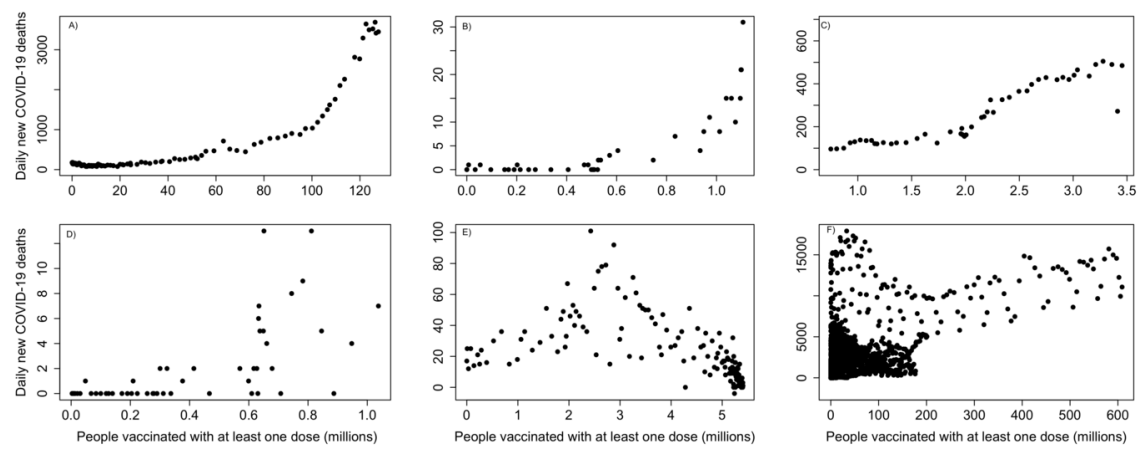

Figure 1: Number of new COVID-19 deaths in relation to number of people that have received at least one vaccine dose for selected countries. Graph shows data from the start of vaccination to May $3^{\text {rd }}, 2021$. A) India (9.25\% of population vaccinated), B) Thailand (1.58\% of population vaccinated), C) Colombia $(6.79 \%$ of population vaccinated), D) Mongolia (31.65\% of population vaccinated), E) Israel (62.47\% of population vaccinated), F) Entire world (7.81\% of population vaccinated). Graphs were built using data from Our World in Data (accessed 4 May 2021) https://github.com/owid/covid-19-data/tree/master/public/ data/vaccinations.

[1] (https://www.gov.uk/government/publications/covid-19-reported-sars-cov-2-deaths-inengland/covid-19-confirmed-deaths-in-england-report 